\title{
Egyptian Fractions Revisited
}

\author{
Olga KOSHELEVA \\ Department of Teacher Education, University of Texas at El Paso \\ El Paso, Texas 79968, USA \\ e-mail: olgak@utep.edu

\section{Vladik KREINOVICH} \\ Department of Computer Science, University of Texas at El Paso \\ El Paso, Texas 79968, USA
}

Received: November 2007

\begin{abstract}
It is well known that the ancient Egyptians represented each fraction as a sum of unit fractions - i.e., fractions with unit numerators; this is how they, e.g., divided loaves of bread. What is not clear is why they used this representation. In this paper, we propose a new explanation: crudely speaking, that the main idea behind the Egyptian fractions provides an optimal way of dividing the loaves. We also analyze the related properties of fractions.
\end{abstract}

Keywords: Egyptian fractions, optimization, educational impact.

\section{What Are Egyptian Fractions}

It is known that people of ancient Egypt represented fractions as sums of unit fractions - i.e., fractions of the type $\frac{1}{n}$. This representation is described, in detail, in the Rhind (Ahmes) Papyrus, the most extensive Egyptian mathematical papyrus; see, e.g., (Boyer and Merzbach, 1991). According to the papyrus, this was a method recommended, e.g., for dividing loaves of bread between several people.

For example, the number $\frac{5}{6}$ can be represented as

$$
\frac{5}{6}=\frac{1}{2}+\frac{1}{3}
$$

In other words,

$$
5=6 \cdot\left(\frac{1}{2}+\frac{1}{3}\right)=6 \cdot \frac{1}{2}+6 \cdot \frac{1}{3}
$$

So, according to the method described in the Rhind Papyrus, if we want to divide 5 loaves between 6 people, we must:

- divide $6 \cdot \frac{1}{2}=3$ loaves into two equal parts each, and 
- divide $6 \cdot \frac{1}{3}=2$ loaves into three equal parts each.

As a result, we get six half-loaves and six third-loaves. Each of the six people receives one half and one third:
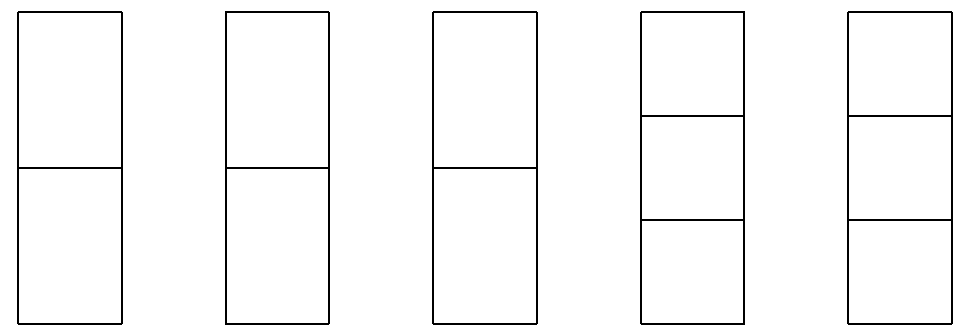

\section{Why Egyptian Fractions? A Question}

Most algorithms with Egyptian fractions are so complicated that it is puzzling why they were used in the first place. For example, according to (Hoffman, 1998), R. Graham (who wrote his $\mathrm{PhD}$ dissertation on unit fractions) asked André Weil why, and A. Weil answered "They took a wrong turn".

\section{Why Egyptian Fractions: A Possible Answer}

Let us assume that we can only divide loaves into equal pieces. One cut divides a loaf of bread into 2 equal pieces. In general, to divide a loaf into $q$ equal pieces, we need $q-1$ cuts.

If we want to divide 5 loaves between 6 people, to give each of them $\frac{5}{6}$ of a loaf, then a natural way to do it is to divide each of 5 loaves into 6 equal pieces. To divide each loaf, we need $6-1=5$ cuts, so to divide all 5 loaves, we need $5 \cdot 5=25$ cuts.

On the other hand, in the Egyptian fraction approach, we need to divide 3 loaves in half ( 1 cut each) and 2 loaves into three equal pieces ( 2 cuts each), to the total of $3+2 \cdot 2=7 \ll 25$ cuts.

\section{General Question: What is the Smallest Number of Cuts?}

Suppose that we want to divide a large number of loaves in such a way that every person gets $\frac{p}{q}$ th of a loaf. In other words, for some large number $N$, we have $N$ people, and we want to distribute

$$
N \cdot \frac{p}{q}
$$

loaves between these people. 
The straightforward way would be to divide each loaf into $q$ equal parts. A more general approach is to divide some loaves into $q_{1}$ equal parts, some loaves into $q_{2}$ equal parts, etc., and some loaves into $q_{k}$ equal parts. Then, we give each person some pieces from each of these divisions:

- some number of parts $\frac{1}{q_{1}}$; we will denote this number by $p_{1}$;

- some number of parts $\frac{1}{q_{2}}$; we will denote this number by $p_{2}$;

- etc.

In other words, we represent the desired ratio $\frac{p}{q}$ as a sum

$$
\frac{p}{q}=\frac{p_{1}}{q_{1}}+\cdots+\frac{p_{k}}{q_{k}}
$$

for natural numbers $p_{i}$ and $q_{i}$.

Each representation of this type corresponds to a possible way of cutting loaves of bread. To find out how we can minimize the number of cuts, let us find out how many cuts per loaf correspond to a representation (1). For $N$ people, we need

$$
N \cdot \frac{p}{q}
$$

loaves, out of which:

- $N \cdot \frac{p_{1}}{q_{1}}$ loaves are divided into $q_{1}$ equal pieces,

- $N \cdot \frac{p_{2}}{q_{2}}$ loaves are divided into $q_{2}$ equal pieces,

- etc.

To divide a loaf into $q_{i}$ pieces, we need $q_{i}-1$ cuts, so the overall number of cuts is equal to

$$
\begin{aligned}
N & \cdot \frac{p_{1}}{q_{1}} \cdot\left(q_{1}-1\right)+\cdots+N \cdot \frac{p_{k}}{q_{k}} \cdot\left(q_{k}-1\right) \\
& =N \cdot\left(p_{1}+\cdots+p_{k}\right)-N \cdot\left(\frac{p_{1}}{q_{1}}+\cdots+\frac{p_{k}}{q_{k}}\right) .
\end{aligned}
$$

Due to (1), we conclude that the for $N$ persons, the overall number of cuts is equal to

$$
N \cdot\left(p_{1}+\cdots+p_{k}\right)-N \cdot \frac{p}{q}
$$

Thus, the average number of cuts per person is equal to

$$
p_{1}+\cdots+p_{k}-\frac{p}{q}
$$

So, the average number of cuts is the smallest if and only if the sum $p_{1}+\cdots+p_{k}$ of the numerators in the representation (1) attains the smallest possible value. 
DEFINITION 1. For every positive rational number

$$
r=\frac{p}{q}
$$

let us denote, by $\|r\|$, the smallest possible sum $p_{1}+\cdots+p_{k}$ among all representations of type (1).

In these terms, the smallest possible number of cuts per person is equal to $\|r\|-r$. What are the properties of this function $\|r\|$ ?

\section{PROPOSITION 1.}

1. For every rational number, we have

$$
\|r\| \geqslant r
$$

2. For every integer $n$, we have

$$
\|n\|=n
$$

3. For every rational number $r$ and for every integer $n$, we have

$$
\left\|\frac{r}{n}\right\| \leqslant\|r\| .
$$

4. For every two rational numbers $r$ and $r^{\prime}$, we have

$$
\left\|r+r^{\prime}\right\| \leqslant\|r\|+\left\|r^{\prime}\right\|
$$

and

$$
\left\|r \cdot r^{\prime}\right\| \leqslant\|r\| \cdot\left\|r^{\prime}\right\|
$$

Proof. Since $\|r\|-r$ is the average number of cuts, i.e., a non-negative number, we have $\|r\| \geqslant r$. The first property is proven.

For integers $n$, we do not need any cuts, so $\|n\|-n=0$ and $\|n\|=n$. Thus, the second property is proven as well.

Let us prove the third property. Let

$$
r=\frac{p_{1}}{q_{1}}+\cdots+\frac{p_{k}}{q_{k}}
$$

be a representation corresponding to $\|r\|$, i.e., representations for which

$$
\|r\|=p_{1}+\cdots+p_{k}
$$


Then,

$$
\frac{r}{n}=\frac{p_{1}}{n \cdot q_{1}}+\cdots+\frac{p_{k}}{n \cdot q_{k}}
$$

For this representation of $\frac{r}{n}$, the sum of the numerators is the same, i.e., it is equal to $\|r\|$. Thus, the smallest possible sum $\left\|\frac{r}{n}\right\|$ of the numerators in the representation of $\frac{r}{n}$ cannot exceed $\|r\|$. The third property is proven.

Let us prove the fourth property. Let

$$
r=\frac{p_{1}}{q_{1}}+\cdots+\frac{p_{k}}{q_{k}}
$$

and

$$
r^{\prime}=\frac{p_{1}^{\prime}}{q_{1}^{\prime}}+\cdots+\frac{p_{k^{\prime}}^{\prime}}{q_{k^{\prime}}^{\prime}}
$$

be representations corresponding to $\|r\|$ and $\left\|r^{\prime}\right\|$, i.e., representations for which

$$
\|r\|=p_{1}+\cdots+p_{k}
$$

and

$$
\left\|r^{\prime}\right\|=p_{1}^{\prime}+\cdots+p_{k^{\prime}}^{\prime}
$$

Then, for the sum of these representations, we get

$$
r+r^{\prime}=\frac{p_{1}}{q_{1}}+\cdots+\frac{p_{k}}{q_{k}}+\frac{p_{1}^{\prime}}{q_{1}^{\prime}}+\cdots+\frac{p_{k^{\prime}}^{\prime}}{q_{k^{\prime}}^{\prime}}
$$

with

$$
p_{1}+\cdots+p_{k}+p_{1}^{\prime}+\cdots+p_{k^{\prime}}^{\prime}=\|r\|+\left\|r^{\prime}\right\|
$$

Thus, the smallest possible sum $\left\|r+r^{\prime}\right\|$ of the numerators in the representation of $r+r^{\prime}$ cannot exceed $\|r\|+\left\|r^{\prime}\right\|$.

Similarly, for the product

$$
r \cdot r^{\prime}=\left(\frac{p_{1}}{q_{1}}+\cdots+\frac{p_{k}}{q_{k}}\right) \cdot\left(\frac{p_{1}^{\prime}}{q_{1}^{\prime}}+\cdots+\frac{p_{k^{\prime}}^{\prime}}{q_{k^{\prime}}^{\prime}}\right)=\sum_{i, j} \frac{p_{i} \cdot p_{j}^{\prime}}{q_{i} \cdot q_{j}^{\prime}},
$$

the sum of the numerators is equal to

$$
\sum_{i, j}\left(p_{i} \cdot p_{j}^{\prime}\right)=\sum_{i} p_{i} \cdot \sum_{j} p_{j}^{\prime}=\|r\| \cdot\left\|r^{\prime}\right\|
$$


so $\left\|r \cdot r^{\prime}\right\| \leqslant\|r\| \cdot\left\|r^{\prime}\right\|$.

The fourth property is proven, so the proposition is proven.

REMARK 1 . We can thus say that $\|\cdot\|$ is an integer-valued additive and multiplicative norm on the set of all positive rational numbers.

\section{Computing the Smallest Number of Cuts: Formulation of the Problem}

How can we actually compute the smallest number of cuts, i.e., the norm $\|\cdot\|$ ? This problem is not trivial, because, from the Egyptian papyri, it is known that even for small $q$, we often need large numbers $q_{k}$.

We will show that an algorithm for computing $\|r\|$ is possible.

\section{Reduction to an Auxiliary Algorithm}

In order to compute $\|r\|$, we will first design a sequence of auxiliary algorithms.

Specifically, for every integer $n$, we will design an algorithm $A_{n}$ that checks whether $\|r\| \leqslant n$. By definition of $\|r\|$, this means that this algorithm $A_{n}$ checks whether there exists a representation of a given fraction $r$ as a sum of

$$
p_{1}+\cdots+p_{k} \leqslant n
$$

unit fractions $\frac{1}{q_{i}}$.

For every fraction $r$, the value $\|r\|$ is a positive integer. Thus, once we have designed the auxiliary algorithms $A_{n}$, we can compute $\|r\|$ as follows:

- First, we use the algorithm $A_{1}$ to check whether $\|r\| \leqslant 1$.

- If the algorithm $A_{1}$ concludes that $\|r\| \leqslant 1$, then, since $\|r\|$ is a positive integer, we have $\|r\|=1$. In this case, we return the value $\|r\|=1$ and stop the computations.

- If the algorithm $A_{1}$ concludes that $\|r\|>1$, then we continue.

- Next, we apply the algorithm $A_{2}$ to check whether $\|r\| \leqslant 2$.

- If the algorithm $A_{2}$ concludes that $\|r\| \leqslant 2$, then, since we already know that $\|r\|>1$, we have $\|r\|=2$. In this case, we return the value $\|r\|=2$ and stop the computations.

- If the algorithm $A_{2}$ concludes that $\|r\|>2$, then we continue.

- After that, we apply the algorithm $A_{3}$ to check whether $\|r\| \leqslant 3$.

- If the algorithm $A_{3}$ concludes that $\|r\| \leqslant 3$, then, since we already know that $\|r\|>2$, we have $\|r\|=3$. In this case, we return the value $\|r\|=3$ and stop the computations.

- If the algorithm $A_{3}$ concludes that $\|r\|>3$, then we continue.

- etc. 
For every fraction $r$, by applying the auxiliary algorithms $A_{1}, A_{2}$, etc., we eventually reach the smallest integer $n$ for which $\|r\| \leqslant n$. This integer $n$ is the desired norm $\|r\|$.

To complete the construction of the desired algorithm, we therefore need to construct the auxiliary algorithms $A_{n}$.

\section{Designing the Auxiliary Algorithms $A_{n}$}

We will build the algorithms $A_{n}$ by induction over $n$.

For $n=1$, the algorithm $A_{1}$ follows from the fact that the only way to get

$$
p_{1}+\cdots+p_{k}=\|r\|=1
$$

is to have $p_{1}=1$ and $k=1$. So, only fractions of the type $\frac{1}{n}$ have $\|r\|=1$. Thus, to check whether $\|r\|=1$, it is sufficient to check whether $r$ is a unit fraction.

Let us now suppose that we have already designed an algorithm $A_{n}$. Let us use this algorithm to design a new algorithm $A_{n+1}$ for checking whether

$$
\|r\| \leqslant n+1
$$

To construct this new algorithm, we will use the fact that $\|r\| \leqslant n+1$ means that the given fraction $r=\frac{p}{q}$ can be represented as the sum of $\leqslant n+1$ unit fractions

$$
\frac{p}{q}=\frac{1}{q_{1}}+\cdots+\frac{1}{q_{M}}
$$

for some $M \leqslant n+1$.

Without losing generality, we can assume that $q_{1} \leqslant q_{2} \leqslant \ldots \leqslant q_{M}$. Thus,

$$
\frac{1}{q_{i}} \leqslant \frac{1}{q_{1}}
$$

for all $i$ and hence,

$$
\frac{1}{q_{1}} \leqslant \frac{p}{q} \leqslant \frac{M}{q_{1}}
$$

Since $M \leqslant n+1$, we conclude that

$$
\frac{1}{q_{1}} \leqslant \frac{p}{q} \leqslant \frac{n+1}{q_{1}} .
$$

Thus,

$$
\frac{q}{p} \leqslant q_{1} \leqslant(n+1) \cdot \frac{q}{p} .
$$


There are only finitely many integers $q_{1}$ in the interval

$$
\left[\frac{q}{p},(n+1) \cdot \frac{q}{p}\right] .
$$

So, to check whether $\|r\| \leqslant n+1$, it is sufficient to try all the integers

$$
q_{1} \in\left[\frac{q}{p},(n+1) \cdot \frac{q}{p}\right],
$$

and for each of them, check whether the corresponding difference

$$
d\left(r, q_{1}\right) \stackrel{\text { def }}{=} \frac{p}{q}-\frac{1}{q_{1}}
$$

can be represented as a sum of $\leqslant n$ unit fractions, i.e., whether

$$
\left\|\frac{p}{q}-\frac{1}{q_{1}}\right\| \leqslant n
$$

For each $q_{1}$, this auxiliary checking can be done by the algorithm $A_{n}$. Thus, the algorithm $A_{n+1}$ is designed.

REMARK 2. As we will see from the following examples, these algorithms not only compute the value $\|r\|$ for a given fraction $r$, they also produce the corresponding representation of the fraction $r$ as the sum of $\|r\|$ unit fractions.

\section{Computing the Smallest Number of Cuts: Example}

Let us illustrate this algorithm on the example of the fraction

$$
r=\frac{p}{q}=\frac{4}{5}
$$

In accordance with our general algorithm, we first apply the auxiliary algorithm $A_{1}$. For the given fraction, $q$ does not divide $p$, so $\frac{4}{5}$ is not a unit fraction and thus

$$
\left\|\frac{4}{5}\right\|>1
$$

Let us now check whether $\left\|\frac{4}{5}\right\| \leqslant 2$. According to the above algorithm $A_{2}$, the integer value $q_{1}$ must satisfy the inequality

$$
\frac{5}{4} \leqslant q_{1} \leqslant 2 \cdot \frac{5}{4}
$$


i.e., $1.25 \leqslant q_{1} \leqslant 2.5$. There is only one integer in the corresponding interval, namely, the integer $q_{1}=2$.

We must now use the algorithm $A_{1}$ to check whether the difference

$$
d\left(r, q_{1}\right)=\frac{p}{q}-\frac{1}{q_{1}}=\frac{4}{5}-\frac{1}{2}=\frac{3}{10}
$$

has $\left\|d\left(r, q_{1}\right)\right\| \leqslant 1$. This difference $d\left(r, q_{1}\right)=\frac{3}{10}$ is not a unit fraction, so $\left\|d\left(r, q_{1}\right)\right\|>1$, hence $\left\|\frac{4}{5}\right\|>2$.

Let us now check whether $\left\|\frac{4}{5}\right\| \leqslant 3$. According to the above algorithm $A_{3}$, the integer value $q_{1}$ must satisfy the inequality

$$
\frac{5}{4} \leqslant q_{1} \leqslant 3 \cdot \frac{5}{4}
$$

i.e., $1.25 \leqslant q_{1} \leqslant 3.75$. There are two integers in the corresponding interval, $q_{1}=2$ and $q_{1}=3$. We must now apply the algorithm $A_{2}$ to the corresponding differences

$$
d\left(r, q_{1}\right)=\frac{p}{q}-\frac{1}{q_{1}}
$$

For $q_{1}=2$, the corresponding difference $d(r, 2)$ is equal to

$$
d(r, 2)=\frac{4}{5}-\frac{1}{2}=\frac{3}{10}
$$

Let us apply the algorithm $A_{2}$ to this difference $r \stackrel{\text { def }}{=} \frac{3}{10}$.

According to the algorithm $A_{2}$, we must select an integer $q_{1}^{\prime}$ for which

$$
\frac{10}{3} \leqslant q_{1}^{\prime} \leqslant 2 \cdot \frac{10}{3}
$$

i.e., we must consider $q_{1}^{\prime}=4, q_{1}^{\prime}=5$, and $q_{1}^{\prime}=6$. Already for $q_{1}^{\prime}=4$, the difference

$$
d\left(r^{\prime}, 4\right)=\frac{3}{10}-\frac{1}{4}=\frac{1}{20}
$$

is a unit fraction, so

$$
\left\|\frac{3}{10}\right\|=2
$$

with the corresponding representation

$$
\frac{3}{10}=\frac{1}{4}+\frac{1}{20} \text {. }
$$


Since

$$
\frac{3}{10}=\frac{4}{5}-\frac{1}{2}
$$

we thus conclude that

$$
\left\|\frac{4}{5}\right\|=3
$$

with

$$
\frac{4}{5}=\frac{1}{2}+\frac{1}{4}+\frac{1}{20}
$$

REMARK 3. This is not the only possible representation of the fraction $\frac{4}{5}$ as a sum of three unit fractions: for $q_{1}^{\prime}=5$, we get an alternative representation with the same number of unit fractions:

$$
\frac{4}{5}=\frac{1}{2}+\frac{1}{5}+\frac{1}{10}
$$

It is worth mentioning that, as one can check, the remaining value $q_{1}^{\prime}=6$ (and the values $q_{1}^{\prime}$ corresponding to $q_{1}=3$ ) do not lead to a sum of three fractions.

\section{Discussion: Are Egyptian Fractions Optimal?}

A natural question is: are actual Egyptian fraction representations - as given in the Rhind Papyrus - optimal? Not always.

For example, the Egyptians did not allow identical unit fractions in their representations and had other unclear preferences. As a result, e.g., instead of

$$
\frac{2}{13}=\frac{1}{13}+\frac{1}{13}
$$

they used a representation

$$
\frac{2}{13}=\frac{1}{8}+\frac{1}{52}+\frac{1}{104}
$$

From the viewpoint of the smallest number of cuts, this representation does not make sense: it replaces a representation corresponding to

$$
p_{1}+\cdots+p_{k}=2
$$

with a representation for which

$$
p_{1}^{\prime}+\cdots+p_{k^{\prime}}^{\prime}=1+1+1=3>2,
$$


i.e., with a representation with more cuts.

So, we do not claim that the ancient Egyptian always had it right, what we claim is that their general idea of reducing the sum of the numerators as much as possible seems to be right. From this viewpoint, it will be interesting to further analyze the properties of the norm $\|\cdot\|$.

\section{How We Can Use These Results and Ideas in Education}

In elementary and middle school mathematics, the concept of fractions is one of the most difficult concepts. To master fractions, students have to avoid and overcome numerous misconceptions. Because of this difficulty, researchers in mathematics educations have developed a large number of innovative ways of teaching fractions, to increase the students' interest and motivation. Egyptian fractions, with their non-traditional structure and easy-to-understand techniques, are known to have led to many successful examples of such innovative activities; see, e.g., (Streefland, 1991; Kosheleva and Kreinovich, 2005; Kosheleva and Lyublinskaya, 2006; Kosheleva and Lyublinskaya, 2007a; Kosheleva and Lyublinskaya, 2007b; NCTM, 2009), and (Eppstein, 2009).

Since these examples work so well when teaching schoolchildren, we have taught the corresponding activities to future teachers, in the methods courses at the University of Texas at El Paso. Interestingly, not only the future teachers learned to use these examples, but they got very much interested in these examples themselves. Egyptian fraction ideas helped the future teachers better understand the variety of possible ideas behind the seemingly simple school mathematics, in particular, the multi-faceted nature of the concept of fraction.

The interesting fact about the Egyptian approach to fractions is that, as we have seen in this paper, this approach leads very fast from simple arithmetic to reasonably complex algorithms - when we want not just to represent every fraction in this way, but to get an optimal representation, with the smallest possible number of terms. When presented with these complex algorithms, more computer-advanced students started thinking about possible implementations of these algorithms.

The students were especially intrigued by the fact that while the resulting representation of each fraction is optimal, the algorithm itself may be not be optimal - in the sense that no one has proved that the same representations cannot be obtained by a much faster algorithm. Looking for a faster algorithm, investigating general property of optimal representations - these are the tasks that students are eager to do by programming these problems and by running these programs on different examples.

The interest that these problems raised when teaching computer-skilled future teachers make us believe that this topic can also be of interest to students studying computer science. Their interest may be further enhanced by the following relevant observation about the hardware implementation of arithmetic operations in the modern computers.

Inside the computers, addition is usually performed by using, in effect, the same algorithm that we learn at school. The main difference between our way of adding numbers and computer implementation is that we add decimal numbers, while the computers perform addition on numbers represented in the binary code. 
Similarly, inside the computers, multiplication is performed in a way which is similar to how we multiply:

- multiplying by different digits and then

- adding the results.

In contrast, in the modern computers, division is performed completely differently from how we normally divide. Namely, the computer calculates $\frac{x}{y}$ as the product $x \cdot \frac{1}{y}$, where

- for several basic values $y$, the ratios $\frac{1}{y}$ are pre-computed and stored, and

- the ratios $\frac{1}{y}$ for other values $y$ are computed based on the known (stored) values.

We can summarize this implementation by saying that modern computers use unit fractions - exactly the same ideas as the Egyptians pioneered.

This analogy can go one step further. We have mentioned that it is still not known which algorithms for computing the Egyptian fractions representations are the fastest. Even simple computer experiments, easily started by students, have the potential of leading to interesting observations and results. Similarly, it is not known which algorithms for division lead to the fastest computer implementations. There is also room for computer simulations and experimentations. And who knows, maybe experiments with the millennia-old Egyptian fractions can lead to stimulating new ideas that will help make modern computers faster?

\section{Acknowledgments}

This work was supported in part by NASA grant agreement NCC5-209, by the US National Science Foundations grants EAR-0112968, EAR-0225670, EIA-0321328, and HRD-0734825, and by grants 3T34GM008048-20S1 and 1 T36 GM078000-01 from the US National Institutes of Health.

The authors are thankful to Valentina Dagiene for her encouragement and helpful advice.

\section{References}

Boyer, C.B. and Merzbach, U.C. (1991). A History of Mathematics. Wiley, New York.

Eppstein, D. (2009). Egyptian Fractions Website.

http: //www.ics.uci.edu/ eppstein/numth/egypt/

Gardner, M. (1978). Puzzles and number-theoretic problems arising from the curious fractions of Ancient Egypt. Scientific American, October.

Hoffman, P. (1998). The Man Who Loved Only Numbers: The Story of Paul Erdös and the Search for Mathematical Truth. Hyperion, New York.

Kosheleva, O. and Kreinovich, V. (2005). Egyptian fractions revisited. In Abstracts of the 2005 Meeting of the Southwestern Section of the Mathematical Association of America (MAA), April 1-2, 2005, 6.

Kosheleva, O. and Lyublinskaya, I. (2006). Teaching fractions with the help of Egyptian papyrus and technology. In Abstracts of the Teachers Teaching with Technology T3 Regional Conference "Using Technology to Engage Students in Discovery Learning", Staten Island, New York, November 3-4, 2006. 
Kosheleva, O. and Lyublinskaya, I. (2007a). Can Egyptian papirus enrich our students' understanding of fractions? In Abstracts of the Annual Meeting of the National Council of Teachers of Mathematics NCTM "Mathematics: Representing the Future", Atlanta, Georgia, March 21-24, 2007, 40.

Kosheleva, O. and Lyublinskaya, I. (2007b). Using innovative fraction activities as a vehicle for examining conceptual understanding of fraction concepts in pre-service elementary teachers mathematical education. In T. Lamberg and L.R. Wiest (Eds.), Proceedings of the 29th Annual Meeting of the North American Chapter of the International Group for the Psychology of Mathematics Education PME-NA 2007, Stateline (Lake Tahoe), Nevada, October 25-28, 2007. University of Nevada, Reno, 36-38.

National Council of Teachers of Mathematics NCTM (2009). Egyptian fractions. NCTM Student Math Notes, March.

Streefland, L. (1991). Fractions in Realistic Mathematics Education: A Paradigm of Developmental Research. Kluwer Academic Publishers, Dodrecht, The Netherlands.

O. Kosheleva received her MS degree summa cum laude in mathematics and applied mathematics from Novosibirsk University, Russia, in 1978. After coming to the USA in 1989, she received MS in computer science and $\mathrm{PhD}$ in computer engineering from the University of Texas at El Paso. In Russia, she participated in organizing mathematical olympiads for high school and middle school students, was actively involved in a special outreach program for teaching mathematics to high school students to better prepare them for the university studies, tutored university students in math, and taught mathematics and computer science to engineers. Since 2001, she is teaching at the University of Texas at El Paso. Her research interests include mathematics education in teacher preparation, embedding technology in learning, cognitive growth in elementary and advanced mathematical thinking, curriculum development, mathematics and applied mathematics. She has more than 50 journal publications, more than 70 papers in peer refereed conference proceedings, and more than 140 published conference abstracts. These publications cover different areas of mathematics education, mathematics and applied mathematics.

V. Kreinovich received his MS in mathematics and computer science from St. Petersburg University, Russia, in 1974, and PhD from the Institute of Mathematics, Soviet Academy of Sciences, Novosibirsk, in 1979. In 1975-80, he worked with the Soviet Academy of Sciences, in particular, in 1978-80, with the Special Astrophysical Observatory (representation and processing of uncertainty in radioastronomy). In 1982-89, he worked on error estimation and intelligent information processing for the National Institute for Electrical Measuring Instruments, Russia. In 1989, he was a visiting scholar at Stanford University. Since 1990, he is with the Department of Computer Science, University of Texas at El Paso. Also, served as an invited professor in Paris (University of Paris VI), Hong Kong, St. Petersburg, Russia, and Brazil. Main interests: representation and processing of uncertainty, especially interval computations and intelligent control. Published 3 books, 6 edited books, and more than 700 papers. Member of the editorial board of the international journal "Reliable Computing" (formerly, "Interval Computations"), and several other journals. Co-maintainer of the international website on interval computations http: //www.cs.utep.edu/interval-comp. 


\section{Dar karta apie egiptietiškas trupmenas}

\section{Olga KOSHELEVA, Vladik KREINOVICH}

Žinoma, kad senovès egiptiečiai pripažino tik tokias trupmenas, kurių skaitiklyje yra vienetas. Trupmenas, kuriu skaitiklyje buvo ne vienetas, jie išreikšdavo trupmenu su vienetu skaitiklyje suma. Tokiu būdu jie, pavyzdžiui, dalindavo duonos kepalą. Nèra aišku, kodèl jie naudojo tokị vaizdavimo būdą. Šiame straipsnyje pateikiamas naujas paaiškinimas: egiptietiškos trupmenos užtikrino optimalu duonos dalijimo būdą. Straipsnyje taip pat analizuojamos su tuo susijusios trupmenų savybès. 